now be brought into action. On the third day, blue pill and calomel, with a very small quantity of opium, were prescribed. He was at that time deeply jaundiced, and his bowels, as they had always been, were excessively costive. On the 15th day his mouth was sore; he was then a good deal sunk, his powers seemed to be flagging, and he was ordered ammonia and wine. On the thirty-eighth day a decided improvement, which bad been gradual, was reported. He began to answer questions, though very slowly and confusedly. Both voice, motion, and sensation, were thus in some measure recovered. Ile had also more power in his side, and he was ordered again to take a single grain of calorrel at night, and at the same time to have a hlister, a most efficient romedy, applied to the nape of the reck. On the forty-fourth day from the operation, his gums were again affected, and he was now much better. On the forty-eighth day it is stated that the change was very marked, and from that period he progressively and gradually recovered, sensation, power, volition, and memory, and he now walks about. Indeed he is as well as ever he was; he is getting flesh, he is free from all nervous disorders, and, in short, he may be said to be perfectly restored to health.

Now this is a case of extreme interest and importance. I cannot now improve it by observation as much as it would admit, but shall endeavour to draw from the facts one or two important inferences.

I believe that a simple division of the scalp would have done every whit as much good in this case as the removal of a portion of the bone. There are crowds of cases where relief has been afforded to constitutional symptoms, - by the simple removal of a source of irritation in the neighbourhood of the brain, - so quick, free, and extensive are the connection and sympathy between the pericrarium and the dura mater, which, as you know, is the internal periosteum of the skull. On the other hand, the removal of tumours, the results of wounds of the scalp, has produced most extraordi. nary symptoms in patients. I remember a lady of rank who died in a day or two after having had one of those small cartilaginous encysted tumours taken away, with which the sebaceous texture of the scalp is so frequently affected. I have seen several cases following an injury of the head, in which there has been a painful puffy spot, where a simple incision has been sufficient to remove the irritation of the brain. Sir Benjamin Brodie has also told me of several such cases which he has seen.

It is important to distinguish between symptoms of organic and symptoms of functional disorder. In the present case they were functional. Having removed the exciting cause, the capillary system was acted upon by the mercury. It was now respon- sive to that medicine, though before it was not; and the consequence was, that the circulation of the brain recovered its balance. The whole case was an instance of an incorrect and imperfect balance of the circulation. That realiy was the pathological condition of the case. By setting the capillary system to work, and restoring the secretions, the cerebral functions were reinstated, and all the symptoms disappeared. They did not depend upon anything but the existing source of irritation which 1 have described. Why, gentlemen, a free division of the external jarts would have destroyed the morbid symptoms, and the ship, which would not before respond to the helm, would then have answered it just as she did. It was necessary to resort to an incision, in order to induce the altered action produced by the mercury, and that $\mathbf{I}$ believe is the simple explanation of the whole case. As a practical matter, therefore, be jealous of little tumours, - tender points on the scalp, where a concussion, however slight, where a wound, however small, and received at however remote a period of time, may have been inflicted, on any part of the head. Immediately divide it, and freely too, and you will often find that, in that way, you may remove the symptoms of nervous disorder, whatever characters they may present, the whole system, perhaps, being subjected to derangement.

\section{RUPTURE OF THE TENDON OF THE RECTUS FEMORIS.}

\section{To the Editor of THE LANCET.}

SrR,-The following case of rupture of the tendon of the rectus femoris, by some called dislocation of the patella downwards, is submitted for insertion in your valuable publication. I am, Sir, your obedient servant,

\section{Havant, Hants, 30 th Oct. 1835.}

Mr. P. of Havant, a gentleman of about fifty years of age, tall and stout, was walking down stair's to his parlour, when, just before reaching the last step, he slipped, and fell with great violence, forwards, on his right knee, on the floor of the hall. On being: assisted up and attempting to walk, he found that he was incapable of advancing the right leg. On my being sent for immediately afterwards, the nature of the accident was soon apparent, for on placing my finger horizontally above the patella, it sunk into a deep hollow, and the edge of the raptured tendon could be distinctly felt. Having placed the patient in bed, in the sitting posture, with the right leg raised considerably higher than the left, and resting on a 
pillow, the inflammatory symptoms were subdued by means of leeches and evaporat. ing lotions. I afterwards applied a bandage from the foot to above the knee, putting a slight compress on the patella. The same position of the body was strictly observed for nearly a month, when the union was complete. Mr. P. can now, three months since the accident, walk nearly as well as ever.

\section{INCISED WOUND OF THE PATELLA.}

\section{To the Editor of The LANCET.}

SIR,-The following case of severe wound of the knee may not be unaccsptable to your readers. I am, Sir, your obedi int servant, J. L. M Carthy, M.D.

Macroom, Oct. 26, $18: 35$.

On the 15 th of the present month, I was called to see Johr Lordan, xtat. 22, a carpenter, a stout healthy young man, who, three days previous to my visit, fell, while in his workshop, when his knee came in contact with an " inch-and-a-quarter dubbing chisel," which was lying with its sharp end upwards. The instrument cut through the integuments and membrares over the patella, and penetrated that bone to the depth of one line. Much tumefaction immediately arose about the joint, extending to some distance up the thigh and down the leg. The pain was so extreme as to prevent sleep for two nights, during which he had also some delirium and headache. His councenance was flushed; the tongue covered with a white fur, moist at the edges, but brown and dry in the centre, towards its posterior part. Pulse 122, full, and bounding; no alvine evacuation for fifty hours; urine scanty and high-coloured.

I removed a piece of adhesive plaster that covered the wound, which was about an inch and $a$ half in length. The edges retracted for the space of a line and a half, the interval being filled with a rusty, brownish matter, and almost dry. He had been to the dispensary in this town on the day on which the accident occurred, when the adhesive plaster was applied.

I bled him to syncope, applied a poultice of oatmeal and linseed to the knee, and prescribed a bolus of calomel, jalap, scammony, cam phor, \&c., and in two hours after, a tablespoonful of the following mixture to be repeated every hour, until the bowels and stomach were affected:- $B_{0}$ Antimonii et Potassce Tartrat. gr. ij; Magnesice Sulphat. $z_{j}$; Aquce $3 \times 1 j$. The medicine operated once by vomiting and twice by stool, and copi.ously. There still remained so much tension of the system, that I again bled him to the amount of twenty ounces, and pre. scribed an anodyne draught. $\mathrm{l} z$ Aque $A m$ mon. Acet. ziss; Mist. Camph. $3 \mathrm{j}$; Vin. Ipecac. gtt. xxx; et Tinct. Hyos. $3 \mathrm{j}$; and a cathartic draught to be taken early next morning.

Oct. 16. No effect from the cathartic draught. Slept a little last night, and seems easicr to-day, but still complains of much pain in the knee, which is much swollen; the integuments are tense, red, and shining; pulse 100, but soft; countenance less flush$\mathrm{ed}$; tongue still furred; thirst urgent; urine still scanty ; skin hot, harsh, and dry. Repeated the saline antimonial solution of yesterday, until the bowels were affected; a bolus in the evening. Bo Ext. Hyosciam. Эj; Pulv. Ipecac. gr. ij ; Potass. Nitrat.gr.v lit. bolus. Two drachms of laudanum to be added to each poultice, as yesterday; renew the poultice four times in the twentyfour hours.

17. Considerably better. The wound much cleaner, and beginning to suppurate freely. His diet had been until to-day entirely limited to diluent drinks. Repet. catap. c. Tinct. Opii ut hein, et sum. haust. ex Olei Ric. $3 \mathrm{j}$ et Tinct. Opii gtt. xvi, c. $/ q$. Cinnam. ३iss. At night an anodyne bolus of Extract of Henbane gr. xvi, and Ipecac. gr. ij.

18. Much better; one copious stool from the draught yesterday. Slept well ; inflammation of the knee entirely alated, except immediately at the edges of the wound; to which spot the pain is also confined. The cut is granulating, and the patient can, for the first time since the accident, flex the joint without pain. Repet. cataplas. sine tinct. opii. Omit olea. Broth and vegetables for dinner.

20. Allowed to get ont of bed, and to omit the poultices. Apply lint to the wound, moistened with a solution of sulph. of zine and comp. spt. of lavender. On the 24 th inst. he was able to return to his work.

This case illustrates two things in the treatment of wounds. First, the advantage of combining anodynes, both locally and generally, with antiphlogistic remedies; and, secondly, the mischievous effects that frequently follow the application of the resinous adhesive plaster to recent wounds.

A Theoretical and Practical Treatise on the Diseases of the Skin. By P. RAYER, M.D. 2nd Edition, entirely remodelled. With an Atlas, in 4to, of Twenty-six Copper Plates, containing Four Hundred Figures, coloured. Bailliere. London. 1835. 8vo. pp. 1835.

The structure of the skin, and the interesting results of Breschet's researches into its intimate tissue, were fully described in our pages a few weeks since. We then deferrcd 